\title{
PERANCANGAN APLIKASI INVENTORY BARANG PT. KFC
}

\author{
Zulfiqri Nuryadi Ahmad \\ Program Studi Informatika, Fakultas Teknik dan Ilmu Komputer, Universitas Indraprasta PGRI \\ Jalan Raya Tengah No 80, Kelurahan Gedong, Pasar Rebo, Jakarta Timur \\ zulfikrinuryadi15@gmail.com
}

\begin{abstract}
Abstrak
Pada inventory barang PT. KFC dalam bagian gudang segala kegiatan keluar - masuk barang masih terbilang manual atau semi - komputerisasi dengan pencatatan dan rekapitulasi menggunakan tulis tangan lalu di-input menggunakan Microsoft Excel. Selama ini inventory barang PT. KFC belum memiliki aplikasi khusus untuk inventory barang sehingga belum sepenuhnya terkomputerisasi yang menyebabkan sistem inventory keluar masuk barang menjadi kurang efektif dan efisien pengerjaannya seperti pencatatan data dan rekapitulasi tersebut, serta memerlukan tempat lebih untuk penyimpanan data. Penelitian ini menggunakan tema SMBD dengan metode kuantitatif untuk memproses data berupa angka penghitungan stok barang dan keluar-masuk barang, dengan penggunaanya single user sebagai karyawan pada bagian gudang sehingga menghasilkan sebuah aplikasi untuk inventory barang dalam gudang pada penelitian ini. Dengan adanya aplikasi inventory barang, manajemen dan monitoring kegiatan barang dalam gudang akan tersimpan secara rapih, aman dan akurat dalam database yang bersifat sistematis. Meningkatkan kinerja kegiatan karyawan demi menyeimbangkan perkembangan teknologi industri 4.0 dalam segi manajemen maupun monitoring kegiatan inventory barang juga membentuk sistem yang lebih maju dari sebelumnya.
\end{abstract}

Kata Kunci: Aplikasi, inventaris barang, grounded research.

\begin{abstract}
In the inventory of goods PT. KFC in the warehouse part of all the activities out-in the goods are still numbered manual or semi-computerized with the recording and recapitulation using the handwriting and then in-input using Microsoft Excel. So far, the inventory of goods PT. KFC does not have a special application for inventory goods so that it is not fully computerized which causes the inventory exit systementry of goods becomes less effective and efficient in its operation such as recording Data and recapitulation, and require more space for data storage. This research uses SMBD theme with quantitative methods to process data in the form of stock counting of goods and entry of goods, with the use of single user as an employee on the warehouse so as to generate an application for inventory of goods in warehouses in this research. With the application of inventory goods, management and monitoring of goods activities in the warehouse will be stored neatly, securely and accurately in a systematic database. Improve the performance of employees ' activities to balance the development of industrial Technology 4.0 in terms of management and the monitoring of goods inventory activities also form a system that is more advanced than before.
\end{abstract}

Keyword: Application, Inventory stuff, grounded research.

\section{PENDAHULUAN}

Pengolahan barang merupakan salah satu bentuk administrasi perusahaan untuk mendata semua informasi dan data barang yang ada dalam inventory perusahaan agar dapat memudahkan perusahaan untuk memantau barang yang ada pada perusahaan. Inventory merupakan kegiatan atau tindakan inventaris untuk melakukan penghitungan, pengurusan, penyelenggaraan peraturan, pencatatan data dan pelaporan barang milik perusahaan dalam unit pemakaian. Pengolahan data barang inventory yang dilakukan oleh PT. KFC atau Fast Food Indonesia untuk mendata semua barang inventory masih menggunakan pencatatan manual lalu peng-inputan data pada Microsoft Excel, sehingga format yang sudah disediakan dalam pencatatan langsung diolah dalam komputer dan di cetak untuk dibukukan dalam sebuah arsip. Selain itu pihak perusahaan membutuhkan tenaga lebih dan waktu yang lama dalam pengolahan data serta pengulangan langkah kerja untuk mengecek kesalahan pencatatan data manual dan penumpukan data dalam sebuah arsip, yang menimbulkan intensitas human error yang lebih sering terjadi dalam hal pembuatan laporan perbulan juga tempat penyimpanan yang dibutuhkan lebih banyak sehingga menjadikannya kurang efisien. 
Untuk menyeimbangkan serta mengejar kemajuan teknologi yang sangat pesat seperti Industry 4.0 di negara Jerman dan Society 5.0 di negara Jepang yang sudah berjalan, disini perlu adanya peningkatan sistem kerja dimana dalam hal ini sudah 41 tahun berdirinya PT. Fast Food Indonesia (KFC) di Jalan Raya Bogor KM.25 sejak 1978 yang bergerak pada bidang makanan dan minuman cepat saji sangat disayangkan sistem inventory barang dalam perusahaan masih terbilang manual atau semi-komputerisasi karena belum terintegrasi dengan suatu software khusus, oleh karena itu untuk menerapkan sistem komputerisasi penuh demi efektifitas yang lebih tinggi dan semakin mempermudah sistem kerja yang ada sangat diperlukan. Dalam hal ini, diperlukan suatu perancangan pembuatan aplikasi yang berbasis komputerisasi (software) penuh agar lebih baik dalam mengatur dan membangun serta mengelola data suatu perusahaan terhadap kinerja karyawan yang lebih efektif demi tercapainya tujuan perusahaan tanpa mengubah sistem yang sudah ada.

Merancang dan membuat aplikasi inventory barang pada PT. KFC di Jalan Raya Bogor KM.25 yang efektif dan efisien guna membantu manajemen data barang dalam bagian gudang tersebut lebih terkomputerisasi secara penuh. Menghasilkan output yang tepat dan akurat sehingga lebih efektif serta efisien. Hasil penelitian dan rancangan yang dibuat oleh peneliti dapat dimanfaatkan sebagai solusi bagi PT. KFC di Jalan Raya Bogor KM.25 dalam proses mengolah data barang dalam inventory di gudang yang berguna meningkatkan efektifitas pekerjaan dan kinerja terhadap karyawan dan di harapkan memberikan kemudahan yang dibutuhkan bagi perusahaan. Diharapkan dapat menjadi bahan masukan bagi mahasiswa lainnya sebagai referensi, khususnya mengenai Perancangan Aplikasi Inventory Barang PT. KFC, jika ingin menggunakan pembahasan yang sesuai dengan penelitian ini. Dan dari hasil penelitian ini juga diharapkan dapat dikembangkan menjadi lebih baik oleh siapapun yang melakukan penelitian serupa.

Menurut Mohamad Subhan, (2012:109) "proses pengembangan spesifikasi baru berdasarkan rekomendasi hasil analisis sistem". "Sekumpulan aktivitas yang menggambarkan secara rinci bagaimana sistem akan berjalan, hal itu bertujuan untuk menghasilkan produk perangkat lunak yang sesuai dengan kebutuhan user" Satzinger, Jackson, \& Burd (2012:5). "Sebuah proses untuk mendefinisikan sesuatu yang akan dikerjakan dengan mengunakan teknik yang bervariasi serta didalamnya melibatkan depenelitian mengenai arsitektur serta detail mengenai komponen dan juga keterbatasan yang akan dialami dalam proses pengerjaannya" Wicaksono, (2011:140). Serta menurut Pressman, (2012:291) "perancangan yang sesungguhnya merupakan suatu aktivitas rekayasa perangkat lunak yang dimaksud untuk membuat keputusan-keputusan utama seringkali bersifat struktural".

Menurut Pramana, (2012:17) "satu unit perangkat lunak yang dibuat untuk melayani kebutuhan akan beberapa aktivitas seperti sistem perniagaan, game, pelayanan masyarakat, periklanan, atau semua proses yang hampir dilakukan manusia". Sedangkan menurut Asropudin, (2013:109) "software yang dibuat oleh suatu perusahaan komputer untuk mengerjakan tugas-tugas tertentu, misalnya Ms.Word dan Ms.Excel".

Menurut Ristono, (2009:4) "inventory atau sering disebut persediaan merupakan simpanan barangbarang mentah, material atau barang jadi yang disimpan untuk digunakan dalam masa mendatang atau dalam kurun waktu tertentu". Persediaan barang sangat penting dalam suatu perusahaan dalam menghadapi perubahan pasar produksi serta mengantisipasi perubahan harga dalam permintaan barang yang banyak. "Barang persediaan atau inventory adalah barang yang disimpan untuk dipakai dalam produksi atau untuk dijual kepada konsumen" menurut Sukirno, (2017:164).

DFD merupakan salah satu komponen dalam serangkaian pembuatan perancangan sebuah sistem komputerisasi, "DFD menggambarkan aliran data dari sumber pemberi data (input) ke penerima data (output) dan aliran data itu perlu diketahui agar si pembuat sistem tahu persis kapan sebuah data harus disimpan, kapan harus ditanggapi (process) serta kapan harus didistribusikan ke bagian lain" menurut Utami \& Asnawati, (2015:53).

Dalam buku Manajemen Basis Data Mengggunakan MySQL, Yanto, (2016:10) menyatakan "basis data terdiri dari 2 kata, yaitu basis dan data. Basis dapat diartikan sebagai markas, gudang, tempat berkumpul. Sedangkan data adalah fakta yang mewakili suatu objek seperti manusia, barang, hewan peristiwa, keadaan dan sebagainya, yang direkam dalam bentuk angka, huruf, simbol, teks, gambar, bunyi atau kombinasinya". 
Menurut Sulianta, (2017:12) "Entity Relationship Diagram (ERD) merupakan diagram yang digunakan untuk merancang tabel-tabel yang nantinya akan diimplementasikan pada basis data. ERD ini dibentuk berdasarkan tiga elemen, yaitu entitas, atribut, dan relasi”.

\section{PENELITIAN RELEVAN}

Judul: Rancang Bangun Aplikasi Sistem Inventory Berbasis Desktop Menggunakan JSE

Disusun Oleh: Junaidi, Ridwan Arifin dan Amanda Septiani

Tujuan Penelitian: Mengatasi semua kendala diperlukan suatu sistem yang mampu mendata secara otomatis jumlah stok setiap jenis barang, melakukan beberapa pembahasan meliputi analisis, perancangan, uji coba dan implementasi. Hasil dari rancang bangun ini dapat membantu manajemen dalam me-monitoring stok sesuai kebutuhan, dan dapat memperkecil human error serta mampu menciptakan laporan dengan cepat dan akurat.

Hasil Penelitian: Manajemen monitoring lebih terkomputerisasi dengan adanya software khusus inventory yang tercipta.

\section{METODE PENELITIAN}

Metode penelitian yang digunakan oleh peneliti adalah metode grounded (grounded research) yaitu suatu metode penelitian berdasarkan pada fakta dan menggunakan analisis perbandingan dengan tujuan mengadakan generalisasi empiris, menetapkan konsep, membuktikan teori, mengembangkan teori, pengumpulan dan analisis data dalam waktu yang bersamaan. Dalam riset ini data merupakan sumber teori atau teori berdasarkan data. Dalam melakukan penelitian senantiasa diperlukan suatu metode penelitian yang sesuai dengan pokok permasalahan yang akan diteliti, sedang metode penelitian itu sendiri. Suatu metode yang digunakan dalam penelitian yang dapat berbentuk metode penelitian survei, ex post facto, eksperimen, naturalistik, policy researh (penelitian policy), action research (penelitian tindakan), evaluasi, dan sejarah. Penelitian merupakan suatu proses yang bertujuan untuk menemukan, mengembangkan, dan menguji suatu pengetahuan dengan cara mengumpulkan, mencatat, dan menganalisis informasi data yang dilakukan dengan sabar, hati-hati, terencana dan sistematis serta berasarkan ilmu pengetahuan.

Seperti halnya peneliti melakukan internship kerja selama 3 bulan pada PT.KFC untuk mendapatkan fakta di lapangan melakukan pencarian data secara real pada sistem inventory barang dalam gudang PT.KFC, bahwa ditemukan pada sistem inventory barang dalam gudang PT.KFC belum adanya aplikasi khusus untuk sistem inventory barangnya. Kemudian peneliti menerapkan konsep perancangan aplikasi khusus untuk inventory barang dalam gudang sebagai langkah tepat yang digunakan bagi pemecahan masalahnya, dan mengembangkan langkah-langkah teori yang sudah dihimpun dari analisis data-data yang didapat.

\section{Metode Lapangan (Field Research)}

Observasi (Pengamatan Langsung)

Peneliti mempelajari dan mengamati pengolahan data yang terdapat pada PT. KFC serta keterkaitan antara subsistem satu dengan subsistem lainnya. Observasi ini dilaksanakan mulai dari bulan Oktober - Desember 2019 pada PT. KFC, Jalan Raya Bogor KM.25, Kelurahan Susukan, Kecamatan Ciracas, Jakarta Timur 13750.

Interview (Wawancara) dan Dokumentasi

Peneliti melakukan Interview (wawancara) mengenai pengolahan data inventory barang PT. KFC kepada bapak Suparyadi selaku kepala gudang produksi dan Lia salah satu admin gudang. Peneliti melakukan pengumpulan data dengan cara melihat dan mencatat data yang diperlukan pada inventory barang PT. KFC.

\section{Studi Literatur}

Mempelajari buku-buku literatur mengenai menganalisis dan mendesain sebuah sistem. Mempelajari sistem dari perancangan aplikasi inventory barang dan lain yang serupa dengan aplikasi yang akan dibuat. Mempelajari buku-buku Pemrograman Java untuk mengintregasikannya dengan MySQL. Mempelajari buku-buku bangun aplikasi dengan Netbeans 8.2 yang berbasis desktop. Membaca dan memahami beberapa jurnal maupun artikel di internet terkait perancangan aplikasi inventory barang dan rancang bangun aplikasi. 
HASIL DAN PEMBAHASAN

Aturan Bisnis Sistem Diusulkan

Peng-inputan Barang Masuk

Kepala gudang memberikan informasi data barang yang dibutuhkan kepada admin untuk dilakukan peng-inputan data barang yang dibutuhkan kedalam aplikasi.

\section{Peng-inputan Stok Barang}

Staf Gudang melakukan pengecekkan barang masuk yang tiba dan melakukan peng-inputan data stok barang lalu barang disimpan dalam gudang.

\section{Peng-inputan Barang Reject}

Dengan stok barang yang sudah ada staf gudang melakukan penyaringan barang untuk dipilah barang yang tidak layak dan di-input sebagai data barang reject lalu dibuatkan surat jalan kepada driver sebagai pengembalian barang.

\section{Peng-inputan Barang Keluar}

Staf gudang melakukan peng-inputan data barang keluar kedalam aplikasi dari data stok penyimpanan barang yang sudah layak dan membuatkan surat jalan kepada driver untuk pengiriman barang.

\section{Laporan}

Setiap akhir bulan laporan data barang masuk, stok barang, barang reject dan barang keluar diserahkan kepada manager gudang yang dicetak dari aplikasi.

\section{Diagram Konteks Sistem yang Diusulkan}

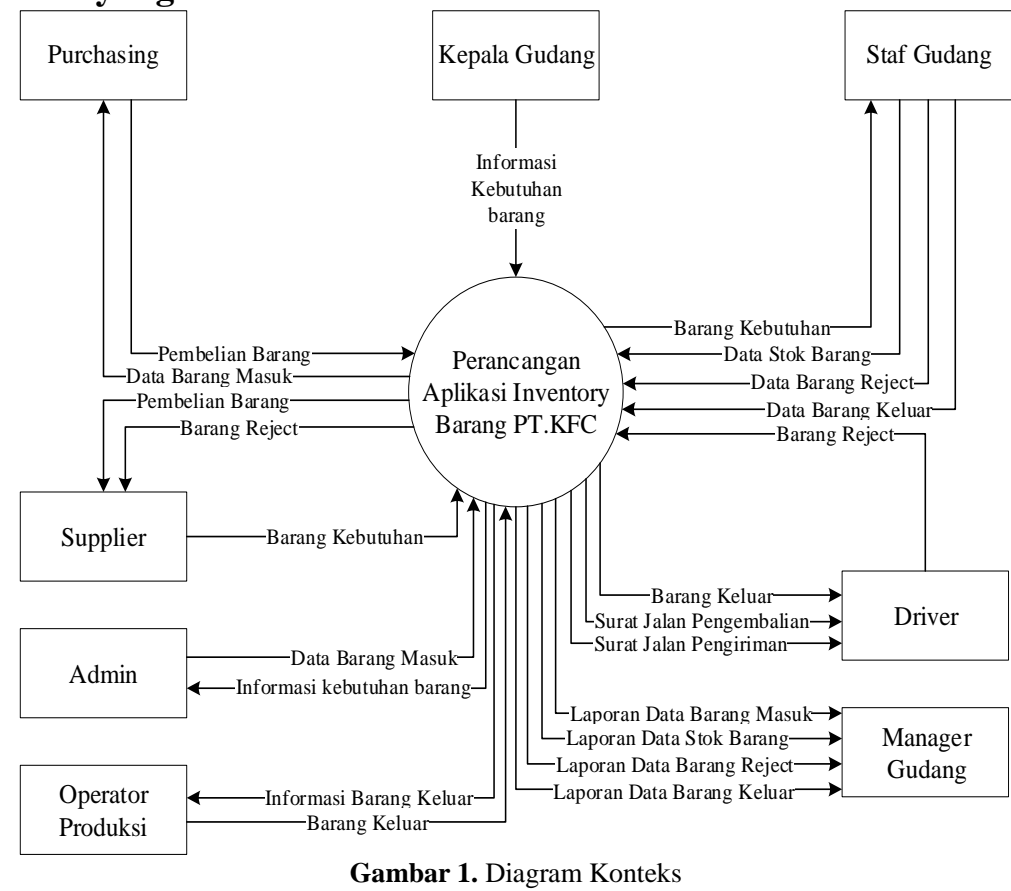

Merupakan konsep diagram alur data sistem yang di terapkan dalam penelitian ini untuk menentukan arus data dari entitas ke entitas yang lainnya. 


\section{ERD (Entity Relationship Diagram)}

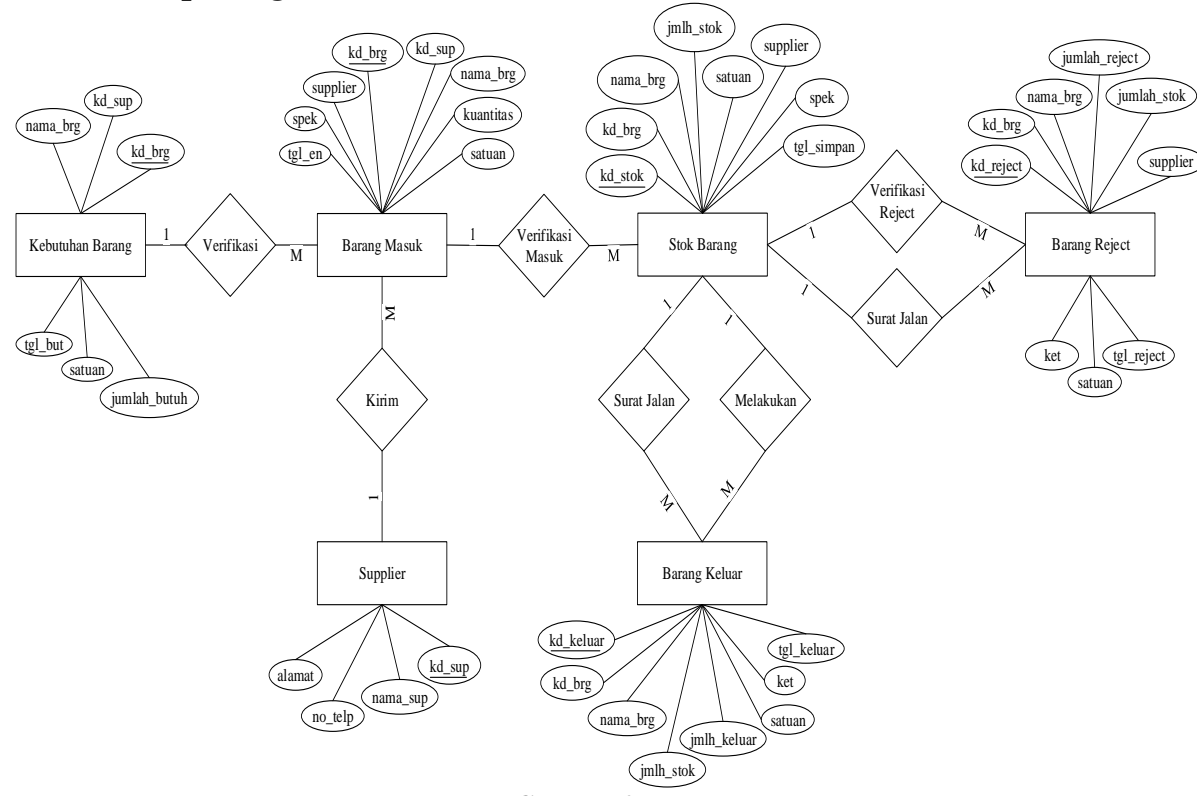

Gambar 2. ERD

Relasi atau hubungan yang ada dalam database dari aplikasi pada tiap-tiap form-nya merupakan hasil yang dibuat dalam penelitian ini.

\section{Tampilan Layar}

Berikut tahap implementasi dan pengujian pada software program yang telah di buat dengan bahasa pemrogram java.

a. Tampilan Menu Utama

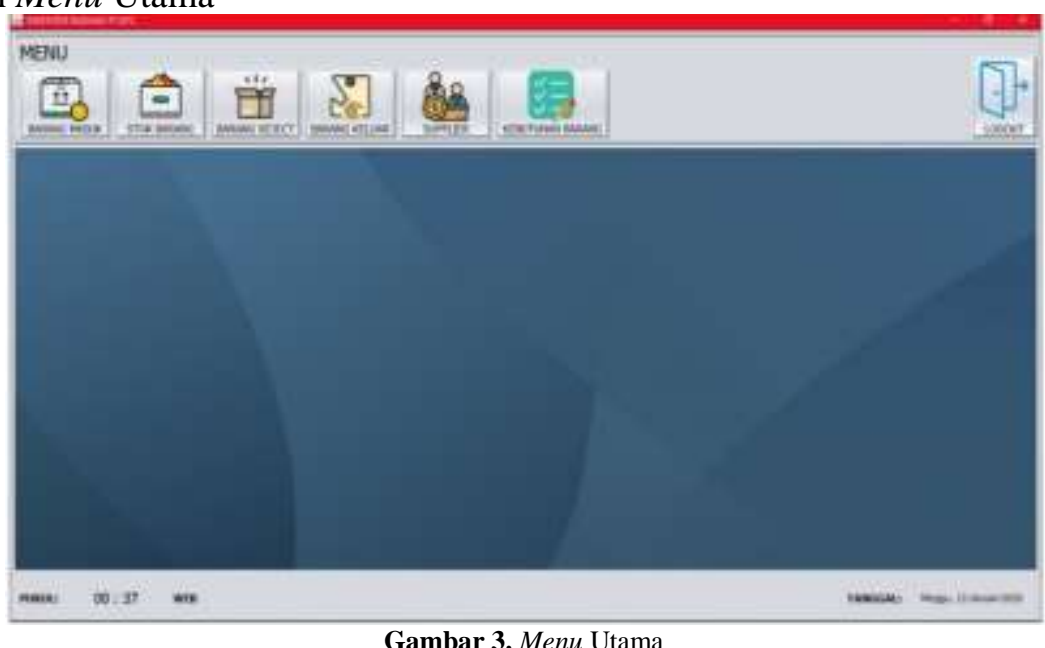

Tampilan menu utama dari aplikasi yang dihasilkan dari penelitian ini untuk memilih тепи sesuai kegiatan yang dibutuhkan. 
b. Tampilan Menu Barang Masuk

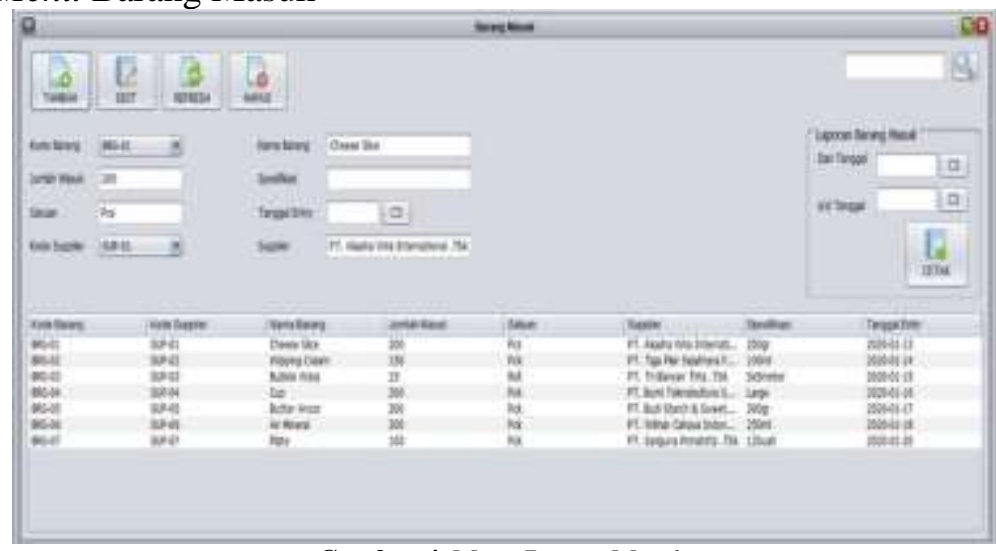

Gambar 4. Menu Barang Masuk

Tampilan menu barang masuk ini untuk mengeksekusi kegiatan data barang masuk yang terjadi pada inventory barang dalam gudang.

c. Tampilan Menu Stok Barang

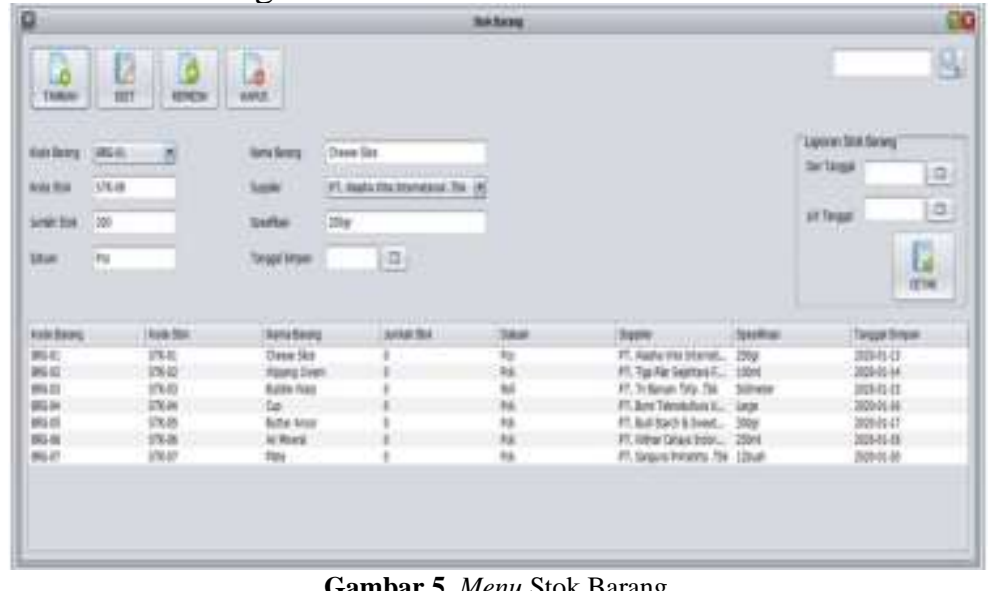

Gambar 5. Menu Stok Barang

Tampilan mеnu stok barang ini untuk mengeksekusi kegiatan data stok barang yang terjadi pada inventory barang dalam gudang.

d. Tampilan Menu Barang Reject

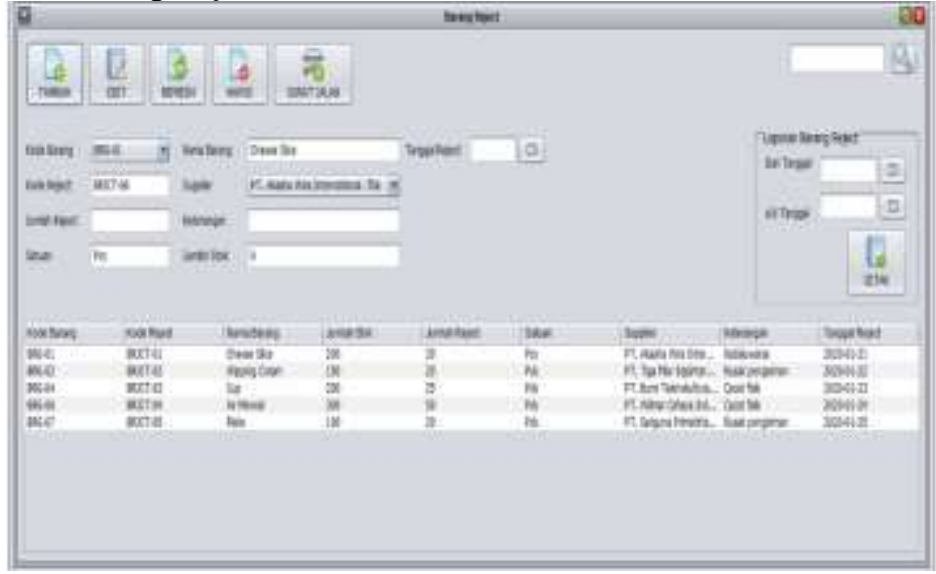

Gambar 6. Menu Barang Reject

Tampilan menu barang reject ini untuk mengeksekusi kegiatan data barang reject yang terjadi pada inventory barang dalam gudang. 
e. Tampilan Laporan Barang Masuk

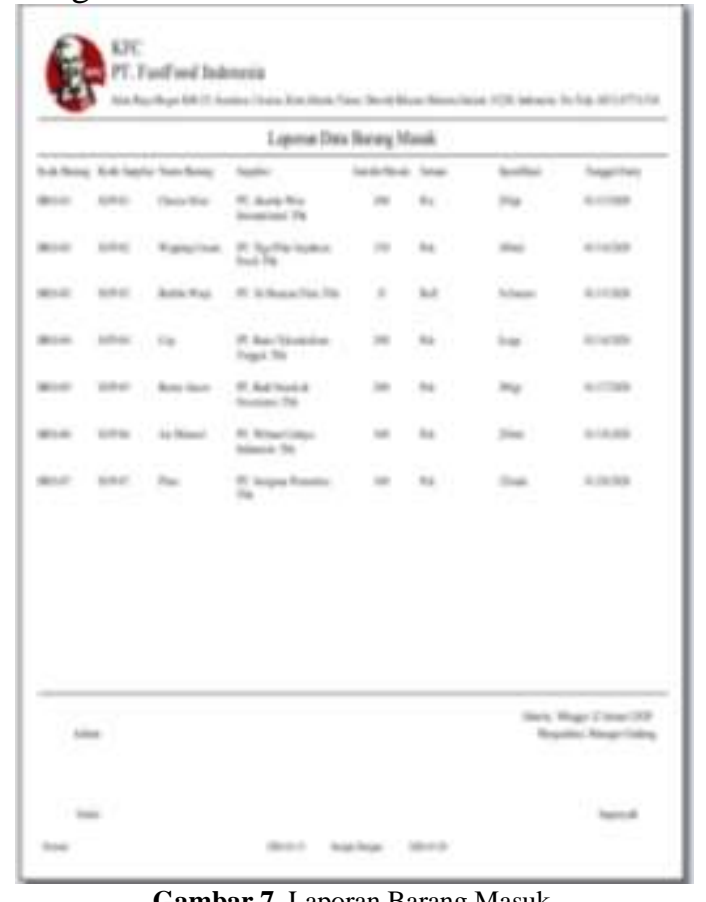

Gambar 7. Laporan Barang Masuk

Berisi data-data bulanan terkait barang masuk pada inventory barang dalam gudang merupakan hasil keluaran dari aplikasi yang dibuat pada penelitian ini.

f. Tampilan Laporan Stok Barang

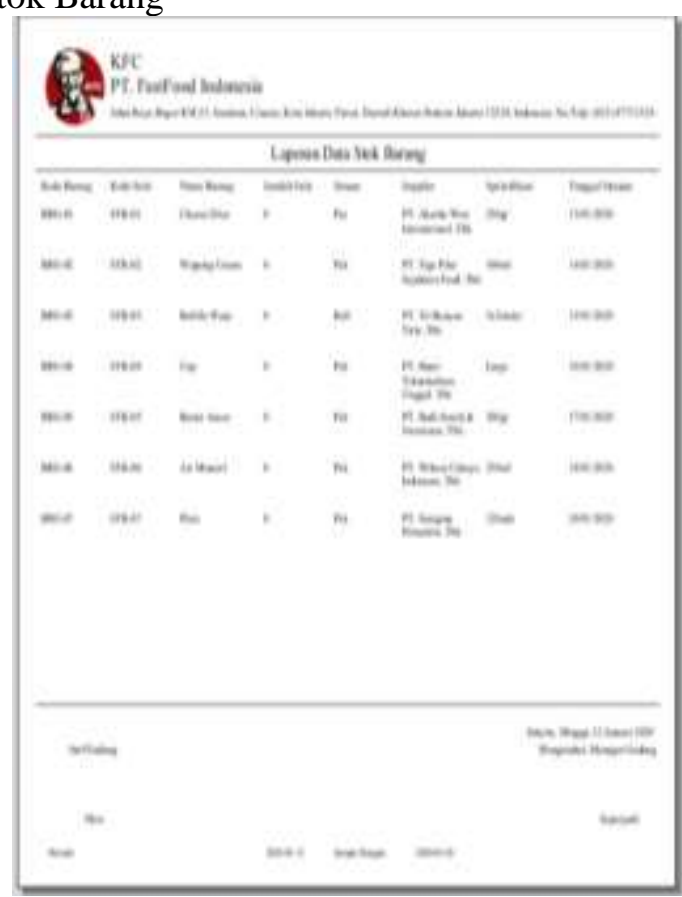

Gambar 9. Laporan Stok Barang

Berisi data-data bulanan terkait stok barang pada inventory barang dalam gudang merupakan hasil keluaran dari aplikasi yang dibuat pada penelitian ini. 


\section{g. Tampilan Laporan Barang Reject}

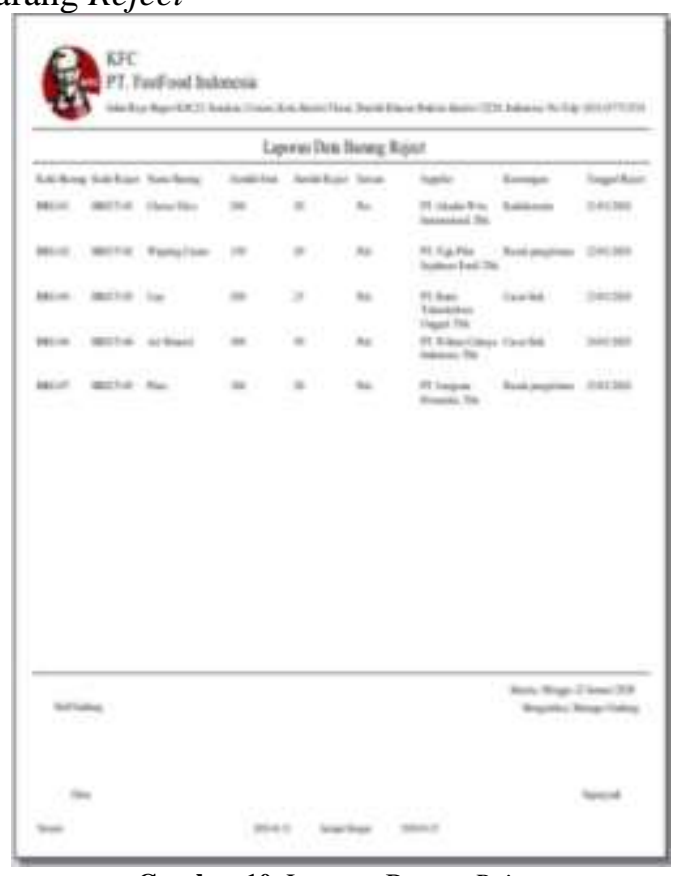

Gambar 10. Laporan Barang Reject

Berisi data-data bulanan terkait barang reject pada inventory barang dalam gudang merupakan hasil keluaran dari aplikasi yang dibuat pada penelitian ini.

\section{SIMPULAN}

Kecepatan dan ketepatan hasil aplikasi ini juga membutuhkan partisipasi aktif dari pemakai aplikasi, terutama kedisiplinan para pelaksana yang menangani secara langsung pada aplikasi yang dirancang. Dengan adanya fasilitas komputer sebagai alat bantu, peneliti mempunyai kesimpulan dengan menggunakan aplikasi ini dapat memberikan beberapa keuntungan sebagai berikut: Penggunaan aplikasi inventory barang memudahkan para karyawan bagian gudang untuk memonitoring dan memanajemen keluar masuk barang juga penyimpanan barangnya dalam gudang. Aplikasi inventory barang ini dapat meningkatkan pemberdayaan SDM sehingga ruang lingkup menjadi modern karena dapat menyeimbangi revolusi industri 4.0 sebagai kemajuan industri dalam bidang makanan cepat saji.

\section{DAFTAR PUSTAKA}

Asropudin. (2013:109). Kamus Teknologi Informasi. Bandung: Titian Ilmu.

Mohamad Subhan. (2012:109). Analisa Perancangan Sistem. Jakarta: Lentera Ilmu Cendekia.

Pramana, H. . (2012:17). Aplikasi Inventory Berbasis Access 2003. Jakarta: PT. Elex Media Komputindo.

Pressman, R. (2012:291). Rekayasa Perangkat Lunak: Pendekatan Praktisi (7 ed.). Yogyakarta: Andi Publisher.

Ristono, A. (2009:4). Manajemen Persediaan. Yogyakarta: Graha Ilmu.

Satzinger, J. W., Jackson, R. B., \& Burd, S. D. (2012:5). Introduction to System Analysis and Design; An Agile, Iterative Approach. USA: Cengage Learning International.

Sukirno, S. (2017:164). Pengantar Bisnis (8 ed.). Jakarta: Kencana.

Sulianta, F. (2017:12). Teknik Perancangan Arsitektur Sistem Informasi. In Teknik Perancangan Arsitektur Sistem Informasi. Jakarta: Elex Media Komputindo.

Utami, F., \& Asnawati. (2015:53). Rekayasa Perangkat Lunak (1 ed.). Yogyakarta: Deepublish.

Wicaksono, S. (2011:140). Konsep Dasar Rekayasa Perangkat Lunak. Jakarta: PT. Prestasi Pustakaraya.

Yanto, R. (2016:10). Manajemen Basis Data Menggunakan MySQL. Yogyakarta: Deepublish. 